\title{
Characterization and Flotation of Sulfur from Chalcopyrite Concentrate Leaching Residue
}

\author{
H. K. Lin \\ Mineral Industry Research Laboratory \\ University of Alaska Fairbanks, Fairbanks, AK 99775-7240
}

\begin{abstract}
Elemental sulfur produced by chloride leaching of sulfide ores or concentrates contains selenium and tellurium usually too high to be used in various industrial or agricultural uses. The sulfur in the leaching residue can be upgraded to $90 \%$ in grade by froth flotation and the sulfur concentration can be followed by sulfur purification and selenium and tellurium removal. The sulfur in the leaching is in a form of discrete particles with a size range of 5 to 10 microns. The sulfur particles tend to agglomerate in the pulp and hence mechanically entrap gangue minerals. With sodium silicate as the dispersant as well as the depressant for siliceous material, a sulfur concentrate of $90 \%$ in grade and $90 \%$ in recovery can be obtained with a single-stage froth flotation. The flotation reagent consumptions are minimum. The majority of chalcopyrite remains in the sulfur flotation tailings and can be readily recovered by flotation with different flotation reagents. When amyl xanthate is used, $85 \%$ of chalcopyrite can be recovered with a copper grade of $14.5 \%$ in a single-stage froth flotation. The chalcopyrite flotation concentrate can be sent back to chloride leaching circuits.
\end{abstract}

Keywords: Elemental sulfur, sodium silicate, dispersant, depressant.

\section{Introduction}

Frash process, a solution mining method operated at an elevated temperature and pressure, has been the major process for producing elemental sulfur in the United States for many decades. But byproduct sulfur produced by petroleum refineries and natural gas processing plants is replacing Frash sulfur in the market. The byproduct sulfur has increased to $60 \%$ of the sulfur production in 1991 from 17\% in 1971 in the United States [1].

Mineral processing played only a small role in the elemental sulfur industry. When a sulfur ore was selected, a typical method was grinding the sulfur ore to about 28 mesh followed by froth flotation. Flotation concentrates were melted and filtered to produce sulfur products with a grade of $99.5 \%$. These plants basically operated before 1960s [2].

Hydrometallurgical processes are playing an increasingly important role in primary production of copper. Copper produced by leaching-solvent extraction-electrowinning accounted for about $30 \%$ of primary refined copper [3].

As early as 1923, ferric chloride leaching was applied to one sulfide ore and was recognized as a highly efficient process [4]. Chloride leaching has become more practical during 
the past three decades as corrosion problems posed by concentrated chloride solution have been at least partially overcome by the advent of modern materials of construction.

The U. S. Bureau of Mines has conducted extensive tests on ferric chloride leaching of chalocopyrite concentrates [5,6]. Many chloride-based hydrometallurgical processes such as: Clear Cymet, Elken, Phelps Dodge and Cuprex processes have been developed to treat copper, copper-lead-zinc concentrates.

Chalcopyrite dissolves in ferric chloride solution and the reactions, depending on the ferric concentration, may be simplified as:

or

$$
\mathrm{CuFeS}_{2}+4 \mathrm{Fe}^{+3}=\mathrm{Cu}^{+2}+5 \mathrm{Fe}^{+2}+2 \mathrm{~S}
$$

$$
\mathrm{CuFeS}_{2}+3 \mathrm{Fe}^{+3}=\mathrm{Cu}^{+}+4 \mathrm{Fe}^{+2}+2 \mathrm{~S}
$$

In the case of pyrite dissolution, the reaction can be expresses as:

$$
4 \mathrm{FeS}_{2}+4 \mathrm{Fe}^{+3}+\mathrm{O}_{2}+2 \mathrm{H}_{2} \mathrm{O}=8 \mathrm{Fe}^{+2}+4 \mathrm{OH}^{-}+8 \mathrm{~S}
$$

Elemental sulfur, which is the predominant solid product of the reactions, can account for more than $50 \%$ by weight of the leaching residue. An economically successful recovery of sulfur will be a great asset to chloride-based hydrometallurgical processes.

Elemental sulfur produced by hydrometallurgical processes usually contains 50-2000 parts per million of selenium and a lesser amount of tellurium; hence, it is not suitable for many industrial or agricultural uses. If the hydrometallurgical sulfur is to be marketable, selenium and tellurium may have to be removed. Otherwise, the sulfur may be considered as an industrial waste rather than a by-product. Dissolution of the sulfur with solvents such as carbon disulfide, xylenes, and tetrachloro-ethylene followed by evaporation fails to remove selenium and tellurium from the sulfur [7].

In recent studies, a process to remove selenium and tellurium from sulfur has been developed [7,8]. In the process, the Se- and Te-containing sulfur was dissolved in an organic solvent such as xylene or tetrachloro-ethylene followed by mixing the solvent with an aqueous solution of a high redox potential. The mixing can be effectively conducted in a mixer-settler unit for a typical solvent extraction operation. Both selenium and tellurium were oxidized in the mixing and thus became very hydrophilic. After the separation of the organic phase from the aqueous phase, sulfur remained in the organic phase and selenium and tellurium in the aqueous phase. A sulfur product with high purity was obtained by crystallization from the organic phase.

However, the cost of the process of removing selenium and tellurium is relatively high. To make the process more economically feasible, the feed to the process should have a high sulfur content.

The objective of this study is to upgrade the sulfur content of the leaching residue of sulfide ores or concentrates through froth flotation technique. The upgraded flotation concentrate 
can serve as the feed for the above-mentioned or similar processes to produce selenium- and tellurium-free sulfur product.

\section{Experimental Work}

Materials. The chalcopyrite leaching residue used in this study was produced from a chalcopyrite concentrate leaching similar to the leaching circuit of the Cuprex process [9]. The leaching conditions are: two-stage countercurrent leaching with 6 hours of retention time on each stage, leaching temperature of $95^{\circ} \mathrm{C}$, and 2.0 moles per liter of ferric chloride. The copper dissolution is $95 \%$.

Chemical analyses of the leaching residue indicate the residue contains: 52\% sulfur, 5\% iron, $2.5 \%$ copper and $31 \% \mathrm{SR}$, where SR indicates the solid leaching residue of aqua regia digestion. Sulfide sulfur and trace elements balance the composition. Elemental sulfur was analyzed by solvent dissolution followed by evaporation of the solvent. Copper and iron were analyzed by aqua regia digestion followed by an atomic absorption spectrometric method.

Pretreatment of the Leaching Residue. Prior to the flotation tests, the sample of the leaching residue was repulped with water to remove residue chemicals which may be carried over from leaching circuits. The clear supernatant was decanted after settlement. The procedures were repeated for 4 times. The repulped sample was then filtered and the cake was fed to the flotation tests.

Flotation Procedure. All flotation tests were conducted at room temperature with a $1000 \mathrm{ml}$ Denver laboratory flotation machine. Pulp density was adjusted to about $30 \%$ solid by weight. The pulp was conditioned in the flotation cell for 10 minutes for each test before air was introduced. Flotation (concentrate collecting) time was set at 4 minutes for each test.

\section{Results and Discussion}

Sulfur Occurrence in the Leaching Residue. While sulfur coating, either porous or protective, on the surface of the sulfide minerals as the results of chloride leaching has been the subject of discussion [10-13], it is clear that the sulfur in this leaching residue is in a form of discrete crystals or crystal agglomerates. Mineralogical examinations on the leaching residue were conducted with scanning electron microscope and microprobe methods. The results reveal that elemental sulfur is in a form of discrete crystal (Figure 1) and the particles tend to agglomerate (Figure 2). No sulfur coating on sulfide minerals or gangues was observed. Chalcopyrite was essentially liberated from gangues or pyrite (Figure 3). The solid residue of aqua regia digestion was mainly quartz with a minor amount of slicates. It is worth noting that a complete dissolution of chalcopyrite particles, of course will produce pure sulfur particles even if sulfur coating occurs initially. However, the size of the sulfur particles, 5-10 microns, is about an order of magnitude smaller than the chalcopyrite or pyrite particles, 40-70 microns, in the leaching residue. It is either that the sulfur coating breaks down as the dissolution progresses or 
the sulfur coating does not occur under the leaching conditions. In either case, the sulfur particles should responds well in the flotation tests.

In the pulp, the fine sulfur particles agglomerate intensely. The agglomeration could result in mechanical entrapment of gangue minerals and thus dilute the grade of the concentrate.

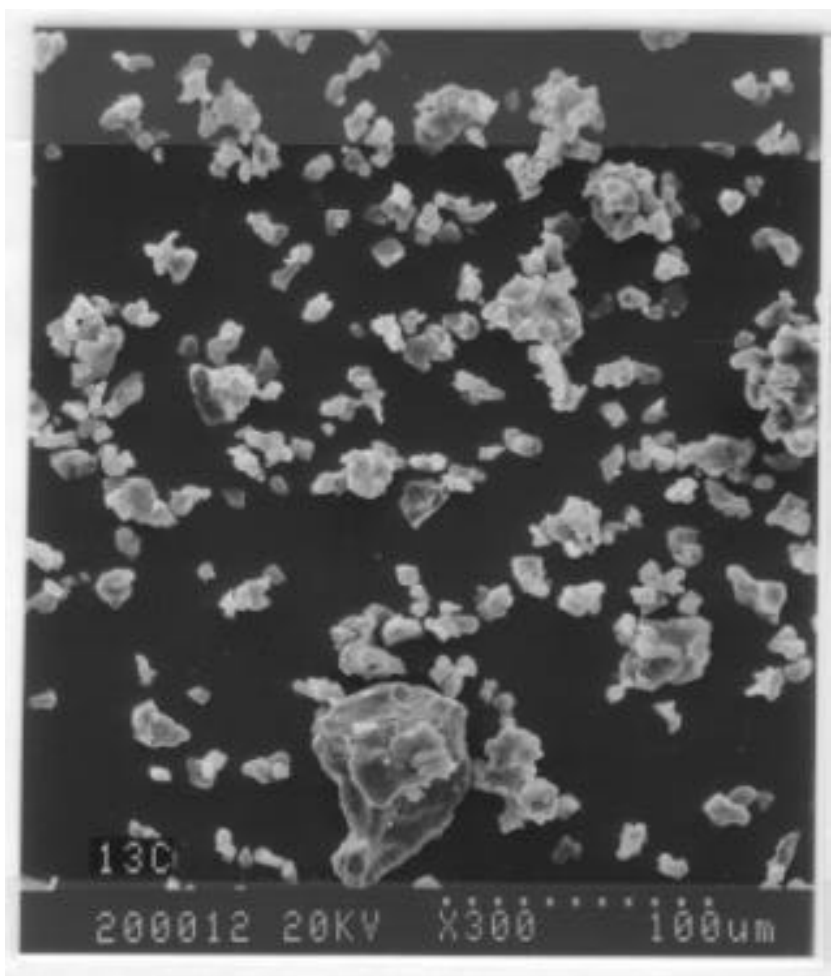

Figure 1. SEM image of sulfur particles in chloride leaching residue. 




Figure 2. SEM image of sulfur agglomerates.

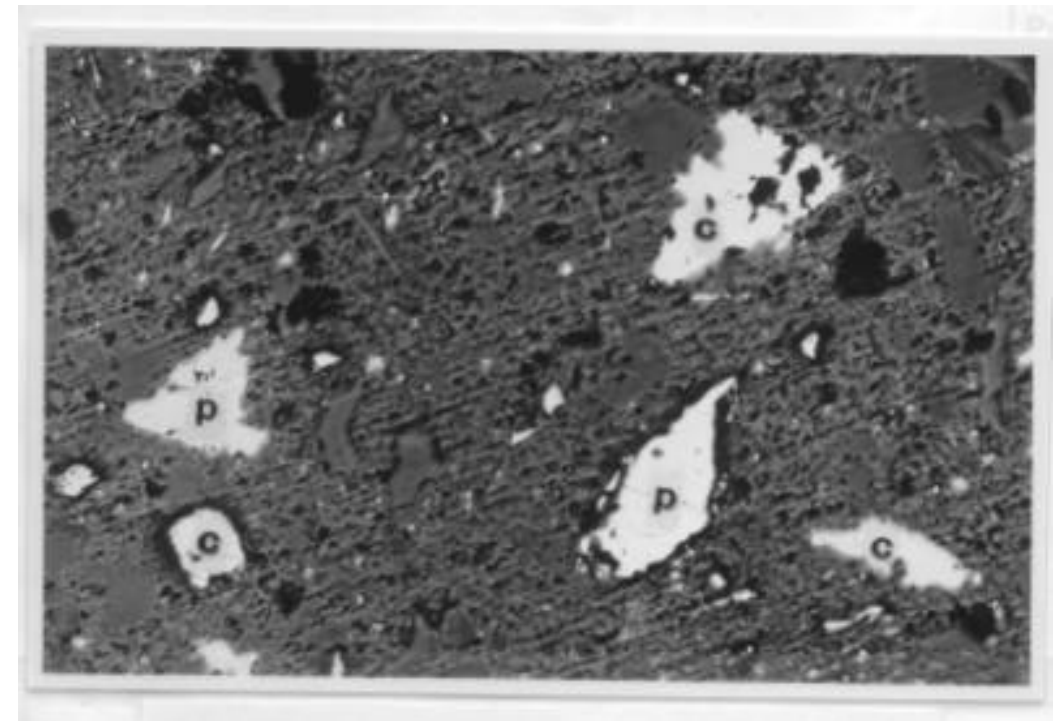

Figure 3. Liberated chalcopyrite and pyrite particles in the leaching residue. c-chalcopyrite, p-pyrite. 
Flotation Tests. Collector, dispersant and $\mathrm{pH}$ are among the parameters examined in the sulfur flotation tests. The tailings from the sulfur flotation were subjected to chalcopyrite flotation to recover copper value.

(a) Effect of collector. Sulfur is known for its hydrophobicity in nature. Discrete sulfur particles can be expected to possess excellent flotability with a small amount of flotation reagent. Preliminary tests show that pine oil and kerosene are effective frother and collector, respectively. The effect of kerosene with $20 \mathrm{~g} / \mathrm{t}$ pine oil at pH 6 is given in Table $\mathrm{I}$.

A kerosene dosage of $20 \mathrm{~g} / \mathrm{t}$ gives a high sulfur recovery of $94 \%$. However, the high grade of siliceous material in the sulfur flotation concentrate dilutes the sulfur grade. The agglomeration of the fine sulfur particles in the pulp with the entrapped gangue minerals results in the relatively low sulfur grade of the concentrate.

Table I. The effect of kerosene on sulfur flotation

\begin{tabular}{|c|c|c|c|c|c|c|c|}
\hline Test & Kerosene, & \multicolumn{3}{|c|}{ Grade, \% } & \multicolumn{3}{|c|}{ Recovery, \% } \\
\hline No. & $\mathrm{g} / \mathrm{t}$ & $\underline{\mathrm{S}}$ & $\mathrm{Cu}$ & SR & $\underline{S}$ & $\mathrm{Cu}$ & SR \\
\hline 1 & 10 & 71 & 1.5 & 9.5 & 85 & 38 & 18 \\
\hline 2 & 20 & 68 & 1.6 & 10.2 & 94 & 49 & 23 \\
\hline 3 & 40 & 67 & 1.5 & 9.9 & 94 & 44 & 23 \\
\hline
\end{tabular}

SR indicates solid residue of aqua regia digestion.

(b) Effect of dispersants. Additions of dispersants to the sulfur flotation system may be effective to minimize the sulfur agglomeration. Sodium silicate $\left(\mathrm{Na}_{2} \mathrm{SiO}_{3}\right)$, sodium lignin sulfonate and A-23 of Diamond Shamrock product were tested as dispersants. The tests results indicate that sodium silicate is more effective in improving the sulfur grades of concentrate and maintaining high sulfur recoveries than sodium lignin sulfonate or A23. This is probably due to the fact that sodium silicate not only has a dispersing effect but is also known for its depression effect on quartz and silicates in flotation circuits [14].

Additions of three various dosages of sodium silicate to the sulfur flotation were tested. Pine oil of $20 \mathrm{~g} / \mathrm{t}$ and kerosene of $20 \mathrm{~g} / \mathrm{t}$ were also added in each test. Pulp pH was maintained at about 6 . The flotation results are shown in Table II.

Table II. The effect of sodium silicate on sulfur flotation.

\begin{tabular}{|c|c|c|c|c|c|c|c|}
\hline \multirow{2}{*}{$\begin{array}{r}\text { Test } \\
\text { No. }\end{array}$} & \multirow{2}{*}{$\begin{array}{c}\text { Sodium } \\
\text { silicate, } \\
\mathrm{g} / \mathrm{t}\end{array}$} & \multicolumn{3}{|c|}{ Grade, $\%$} & \multicolumn{3}{|c|}{ Recovery, \% } \\
\hline & & $\mathrm{S}$ & $\mathrm{Cu}$ & SR & $\underline{S}$ & $\mathrm{Cu}$ & SR \\
\hline 1 & 25 & $\overline{84}$ & $\overline{1.2}$ & $\overline{4.1}$ & 93 & $\overline{29}$ & 8 \\
\hline 2 & 50 & 89 & $\overline{0.9}$ & 2.9 & 91 & 21 & 5 \\
\hline 3 & 75 & 90 & 0.7 & 3.0 & 92 & 17 & 6 \\
\hline
\end{tabular}

SR indicates solid residue of aqua regia digestion. 
A sodium silicate dosage of $50 \mathrm{~g} / \mathrm{t}$ increases the sulfur grade of the concentrate to $89 \%$ with a recovery of $91 \%$. The grade of both copper and siliceous material has been reduced significantly, indicating a lesser amount of chalcopyrite and siliceous material entrapment in the sulfur agglomeration.

(c) Effect of $\mathrm{pH}$. Slurry $\mathrm{pH}$ decreases gradually during pulping of the sulfur-containing sample. The $\mathrm{pH}$ indicated in the flotation tests is the $\mathrm{pH}$ measured at the start of collecting flotation concentrate. Lime, sodium hydroxide and sodium carbonate were tested as the $\mathrm{pH}$ regulators in the sulfur flotation. Lime was shown to be slightly more effective than the other two $\mathrm{pH}$ regulators. The effect of $\mathrm{pH}$ adjusted by lime is presented in Table III. The experimental conditions include $20 \mathrm{~g} / \mathrm{t}$ of pine oil, $20 \mathrm{~g} / \mathrm{t}$ of kerosene and $50 \mathrm{~g} / \mathrm{t}$ of sodium silicate.

Table III. The effect of pulp pH on sulfur flotation.

\begin{tabular}{|c|c|c|c|c|c|c|c|}
\hline Test & Pulp pH & \multicolumn{3}{|c|}{ Grade, \% } & \multicolumn{3}{|c|}{ Recovery, \% } \\
\hline No. & & $\mathrm{S}$ & $\mathrm{Cu}$ & SR & $\underline{S}$ & $\mathrm{Cu}$ & SR \\
\hline 1 & 4.9 & 90 & 1.3 & 3.8 & 92 & 29 & 7 \\
\hline 2 & 5.9 & 88 & 1.1 & 2.8 & 90 & 23 & 5 \\
\hline 3 & 7.2 & 88 & 1.2 & 3.3 & 89 & 27 & 6 \\
\hline 4 & 8.1 & 83 & 0.9 & 4.1 & 92 & 22 & 7 \\
\hline
\end{tabular}

$\mathrm{SR}$ indicates solid residue of aqua regia digestion.

Sulfur grade decreases slightly with increase of the pulp $\mathrm{pH}$ in the $\mathrm{pH}$ range of 4.98.1. However, sulfur recovery remains high. Both recovery and grade for chalcopyrite and siliceous material in the sulfur concentrates are low. The decreases of the sulfur grade with increase of the pulp $\mathrm{pH}$ in the tested range may be due to elemental sulfur being more stable at a lower $\mathrm{pH}$ in the tested range, while it is more likely to be oxidized to sulfate at a higher $\mathrm{pH}$ [15].

(d) Chalcopyrite flotation on tailings of sulfur flotation. The tailings of sulfur flotation conducted at close to neutral $\mathrm{pH}$ with pine oil, kerosene and sodium silicate as the frother, the collector and the dispersant, respectively contain about $4 \%$ copper and $10 \%$ sulfur. Quartz is the major component in the tailings. Copper in the mineral form of chalcopyrite in the tailings was tested for flotation. The copper flotation tests were conducted at about $30 \%$ solid by weight, $10 \mathrm{~g} / \mathrm{t}$ of pine oil, $10 \mathrm{~g} / \mathrm{t}$ of copper sulfate and $25 \mathrm{~g} / \mathrm{t}$ of potassium amyl xanthate. The $\mathrm{pH}$ of the pulp was adjusted to about 7. The result of chalcopyrite flotation on the tailings of sulfur flotation is given in Table IV.

Table IV. Results of chalcopyrite flotation on tailings of sulfur flotation.

\begin{tabular}{|c|c|c|c|c|c|}
\hline & \multirow[t]{2}{*}{$\mathrm{Wt} \%$} & \multicolumn{2}{|c|}{ Grade, \% } & \multicolumn{2}{|c|}{ Recovery, \% } \\
\hline & & & $\underline{\mathrm{S}}$ & $\mathrm{Cu}$ & $\underline{\mathrm{S}}$ \\
\hline Conc. & 24 & 14.5 & 20.8 & $\overline{85}$ & 51 \\
\hline Tailings & 76 & 0.8 & 6.3 & 15 & 49 \\
\hline Calc. Feed & 100 & 4.1 & 9.8 & 100 & 100 \\
\hline
\end{tabular}


The chalcopyrite in the tailings of sulfur flotation responds well in the chalcopyrite flotation with a copper recovery of $85 \%$. The flotation also recovers about half of the elemental sulfur from the sulfur flotation tailings. The copper concentrate can be directed back to the chloride leaching circuits.

\section{Conclusions}

The elemental sulfur formed during the ferric chloride leaching is discretely crystalline in nature. The size of the sulfur particles is in the range of 5 to 10 microns and is about an order of magnitude smaller than the size of chalcopyrite or pyrite (40-70 microns). The sulfur particles tend to agglomerate intensely in the pulp.

The sulfur responds well to the sulfur flotation at high recoveries, but dispersants are needed to produce flotation concentrates of high sulfur grades. A sulfur flotation with $90 \%$ sulfur grade and $90 \%$ recovery can be achieved. The sulfur flotation concentrate can be treated with an innovative process [7,8] to purify the sulfur to $+99.9 \%$ and simultaneously remove selenium and tellurium.

The residue chalcopyrite of the ferric chloride leaching responds well to flotation in chalcopyrite flotation tests. The chalcopyrite flotation concentrate can be directed back to the leaching circuit. The recovery of chalcopyrite should be taken into consideration when sulfur is further purified from the sulfur flotation concentrates.

\section{References}

1 Edmonson, N., 1994, "North American Sulfur Market: Structure and Outlook", Mining Engineering, Vol 46, No 6, pp563-567.

2 Weiss, N. L., 1985, "SME Mineral Processing Handbook", Society of Mining Engineering, American Institute of Mining, Metallurgical and Petroleum Engineers, Inc., New York, NY, Section 28.

3 U. S. Bureau of Mines, 1990, "Mineral Industry Surveys", Copper Monthly, March, 20p.

4 Christiansen, N. C., 1923, "Process of Treating Ores Containing Galena", U. S. Patent $1,456,784$.

5 Haver, F. P., Baker, R. D., and Wong, M. M., 1975, "Improvements in Ferric Chloride Leaching of Chalcopyrite Concentrate", U. S. Bureau of Mines, RI8007.

6 Philips, T. A., 1976, "Economic Evaluation of a Process for Ferric Chlorite Leaching of Chalcopyrite", U.S. Bureau of Mines IC8699.

7 Lin, H. K., 1996, "Simultaneous Oxidation and Stripping for Separating Se and Te from Sulfur", JOM, Vol 48, No 3., pp50-52.

8 Lin, H. K., and Rao, P. D., 1995, "Process for Removing Selenium form Sulfur", U. S. Patent, 5,378,488.

9 Dalton, R. F., Price, R., Hermana, E., and Hoffman, B., 1988, "Cuprex-New Chloridebased Hydrometallurgy to Recover Copper from Sulfide Ores", Mining Engineering, Vol 40, No 1, pp24-28. 
10 Palmer, B. R., Nebo, C. O., Rau, M. F., and Fuerstenau, M. C., 1981, "Rate Phenomena Involved in the Dissolution of Chalcopyrite in Chloride-bearing Lixiviants", Metallurgical Transaction, Vol 12B, pp595-601,

11 Haver, F. P., and Wong, W. W., 1971, "Recovery of Copper, Iron and Sulfur from Chalcopyrite Concentrate Using a Ferric Chloride Leach", Journal of Metals, Vol 23, No 2, pp25-29.

12 Parker, A. J., Paul R. L., and Power G. C., 1981, "Electrochemical Aspects of Leaching Copper from Chalcopyrife in Ferric and Cupric Salt Solutions", Aust. J. of Chemistry, Vol 34, pp13-34.

13 Dutrizac, J. E., and MacDonald, R. J. C., 1974, "Ferric Ion as a Leaching Medium", Minerals Sci. Engng., Vol 6, No 2, pp59-100.

14 Weiss, N. L., 1985, "SME Mineral Processing Handbook", Society of Mining Engineering, American Institute of Mining, Metallurgical and Petroleum Engineers, Inc., New York, NY, Section 5.

15 Pourbaix, M., 1974, "Atlas of Electrochemical Equilibria in Aqueous Solutions", National Association of Corrosion Engineers, Houston, Texas, p551. 